\title{
Pengaruh Profitabilitas, Ukuran Perusahaan dan Ukuran Dewan Komisaris terhadap Pengungkapan Tanggung Jawab Sosial Perusahaan pada Perusahaan Manufaktur yang terdaftar di Bursa Efek Indonesia
}

\author{
Chelsya \\ Fakultas Ekonomi Universitas Tarumanagara \\ Email: chelsya@fe.untar.ac.id
}

\begin{abstract}
This research aims to determine the factors that influence the level of Corporate Social Responsibility Disclosures by testing the effect of corporate size, profitability, and board of director size on corporate social responsibility disclosures index. Sample used are manufactur sector companies that listed on Indonesia Stock Exchange. The sources of the data were taken from audited financial reports and annual reports and sustainability report, if any. This research uses quantitative approach with multiple linier regression analysis. The results show that profitability, firms' size and board of director size have a positive effect on corporate social responsibility disclosures.
\end{abstract}

Keywords: Corporate Social Responsibility, company size, profitability, board of director size.

\begin{abstract}
Abstrak: Penelitian ini bertujuan untuk menentukan faktor-faktor yang mempengaruhi pengungkapan tanggung jawab sosial perusahaan (Corporate Social Responsibility) dengan menguji pengaruh profitabilitas, ukuran perusahaan, dan ukuran dewan komisaris. Sampel yang digunakan adalah perusahaan manufaktur terdaftar di Bursa Efek Indonesia. Data diperoleh dari laporan keuangan auditan dan laporan tahunan serta laporan keberlanjutan (sustainability report). Penelitian ini menggunakan pendekatan kuantitatif dengan analisis regresi linear berganda. Penelitian ini menunjukkan bahwa profitabilitas, ukuran perusahaan dan ukuran dewan komisaris memiliki pengaruh positif terhadap pengungkapan tanggung jawab sosial.
\end{abstract}

\section{PENDAHULUAN}

Pesatnya perkembangan perekonomian menyebabkan semakin banyak perusahaanperusahaan yang bermunculan sehingga timbul persaingan yang ketat di antara perusahaan-perusahaan tersebut dalam mempertahankan keberadaan dan keberlanjutan usaha. Untuk mempertahankan keberlanjutan usaha, terkadang perusahaan hanya berfokus pada profit semata (profit-oriented) dan pemenuhan kepentingan shareholders saja. Jikalaupun perusahaan memenuhi kepentingan stakeholders, itupun terbatas hanya pada pemenuhan kepentingan pemilik, pemerintah (melalui pembayaran pajak) dan masyarakat (terbatas pada pemenuhan produk dan penyediaan lapangan kerja) tanpa memperhatikan kondisi lingkungan alam dan kesejahteraan masyarakat. Hal ini menyebabkan terjadinya eksploitasi sumber daya alam dan eksploitasi sumber daya manusia yang tidak terkendali sehingga berdampak pada terjadinya pencemaran dan pengrusakan lingkungan alam dan kondisi masyarakat yang kian memburuk baik dari aspek ekonominya maupun 
kesehatannya. Permasalahan inilah yang menimbulkan adanya tuntutan dari berbagai pihak terhadap perusahaan untuk segera melakukan tanggung jawab sosial perusahaan.

Pentingnya pelaksanaan tanggung jawab sosial perusahaan didasarkan pada pandangan bahwa keberadaan dan keberlanjutan usaha setiap perusahaan tidak terlepas dari peran serta Stakeholders. Oleh karena itu dengan adanya tuntutan dari berbagai pihak tersebut mulai menyadarkan perusahaan bahwa untuk keberlanjutan hidup perusahaan (Company Sustainability), tidak hanya dari Profit Maximization tetapi juga dari pelaksanaan tanggung jawab sosial dan lingkungan.

Dalam pengungkapan tanggung jawab sosial perusahaan, diduga dipengaruhi oleh berbagai variabel, antara lain : kinerja keuangan, ukuran perusahaan dan ukuran dewan komisaris. Menurut Zaki Baridwan (2013:11), kinerja keuangan perusahaan tercermin pada profit perusahaan yaitu pada rasio profitabilitas, dimana Return on Assets dan Return on Equity merupakan dua indikator pengukuran untuk mengukur tingkat profitabilitas jangka panjang perusahaan.

Ukuran perusahaan diduga mempengaruhi luasnya pengungkapan tanggung jawab sosial perusahaan karena ukuran perusahaan memiliki hubungan yang erat dengan Agency Theory, dimana perusahaan besar memiliki biaya agensi yang lebih besar sehingga mempunyai insentif yang lebih untuk mengungkapkan informasi yang lebih luas mengenai tanggung jawab sosial dan lingkungan. Perusahaan besar juga mempunyai visibilitas politis yang tinggi sehingga dapat mengungkapkan tanggung jawab sosial perusahaan secara luas untuk mengurangi biaya politis.

Ukuran dewan komisaris diduga mempengaruhi luasnya pengungkapan tanggung jawab sosial perusahaan. Menurut Sembiring (2005:387) dan Krisna (2013:122), semakin banyak jumlah dewan komisaris dalam perusahaan, maka akan semakin mudah untuk mengendalikan $C E O$ dan monitoring yang dilakukan akan semakin efektif. Bila dikaitkan dengan pengungkapan tanggung jawab sosial, maka tekanan terhadap manajemen juga akan semakin besar untuk mengungkapkan tanggung jawab sosial perusahaan.

\section{KAJIAN TEORI}

Tanggung Jawab Sosial Perusahaan. Menurut Lawrence dan Weber (2011:45-46), tanggung jawab sosial perusahaan adalah:

"Corporate Social Responsibility means that a corporation should be held accountable for any of its actions that affect people, their communities, and their environment. It implies that harm to people and society should be acknowledged and corrected if at all possible. It may require a company to forgot some profits if its social impacts seriously hurt some of its stakeholders or if its fund can be used to have a positive social impact."

Kotler dan Lee (2005:3) mendefinisikan tanggung jawab sosial perusahaan sejalan dengan pengertian-pengertian sebelumnya yaitu:

"Corporate Social Reponsibilities is a commitment to improve community wellbeing through discretionary business practices and contribution of corporate resources."

Berdasarkan beberapa definisi yang telah dikemukakan di atas, maka secara umum tanggung jawab sosial perusahaan dapat disimpulkan sebagai suatu komitmen perusahaan 
untuk bertindak etis secara sukarela kepada stakeholders-nya dengan menyeimbangkan diri di antara ekonomi, sosial, dan lingkungan.

Menurut Wibisono (2007:71-72) alasan tanggung jawab sosial perusahaan adalah (1) perusahaan merupakan bagian dari masyarakat dan karena itu perusahaan harus memperhatikan kepentingan stakeholder, (2) untuk menjalin hubungan baik dengan stakeholder agar mendapatkan dukungan, (3) untuk meredam atau menghindari konflik sosial. Dengan demikian dapat disimpulkan bahwa alasan pentingnya bagi perusahaan untuk melakukan tanggung jawab sosial perusahaan adalah untuk mengurangi terjadinya konflik bagi perusahaan sehingga perusahaan dapat hidup berkesinambungan.

Definisi Global Reporting Initiative menurut situs resmi GRI (http://www.globalreporting.org) adalah: "a network-based organization that has pioneered the development of the world's most widely used sustainability reporting framework and is committed to its continuous improvement and application worldwide". GRI Sustainability Reporting Guidelines membagi aspek - aspek yang perlu dilaporkan dalam tanggung jawab sosial perusahaan ke dalam tiga kategori, yaitu : kinerja ekonomi, kinerja lingkungan dan kinerja sosial. Dengan pertimbangan masih adanya perusahaan yang belum berpengalaman, GRI memberikan pilihan dan fleksibilitas bagi penggunanya dalam membuat laporan pertanggungjawaban sosial yang lengkap dan ideal.

Profitabilitas. Menurut Brigham dan Houston (2003: 99), rasio profitabilitas menunjukkan hasil neto dari kebijakan dan keputusan perusahaan. Karena itu, rasio ini menunjukkan keefektifan dari kegiatan operasi perusahaan. Rasio profitabilitas menunjukkan efek kombinasi dari likuiditas, manajemen aset, dan hutang pada kegiatan operasi. Rasio profitabilitas terdiri dari Rasio Return on Assets, Return on Equity, Net Profit Margin, dan Earning per Share. Rumus perhitungan ROA adalah Net Income available to common stockholders dibagi dengan Total Assets.

Ross, Westerfield dan Jordan (2003: 70) mendefinisikan ROA sebagai kemampuan perusahaan menghasilkan laba dari investasi dalam asetnya. Rumus perhitungan ROA adalah Net Income dibagi dengan Total Assets. Menurut Weygandt, Kimmel dan Kieso (2016:222) yang telah mengacu pada IFRS (IFRS based), rumus perhitungan Rate of return on assets adalah Net Income dibagi dengan Average total assets. Perhitungan tersebut digunakan untuk mengukur tingkat profitabilitas keseluruhan dari aset perusahaan.

Menurut Brigham dan Houston (2003: 101), Rasio Return on Equity (ROE) adalah "ratio of net income to common equity". Rumus perhitungan ROE adalah Net income available to common stockholders dibagi dengan Common equity. Menurut Ross, Westerfield, dan Jordan (2003: 70), ROE adalah kemampuan perusahaan untuk menyediakan tingkat pengembalian bagi investasi yang telah dilakukan oleh pemegang saham. Perhitungan ROE adalah Net income dibagi dengan Total equities.

Menurut Weygandt, Kimmel dan Kieso (2016:222) yang telah berkiblat pada IFRS, ROE atau Rate of return on share capital - ordinary dihitung dengan membagi Net Income minus preference dividends dengan Average shareholder's equity - ordinary, di mana perhitungan tersebut digunakan untuk mengukur tingkat profitabilitas atau tingkat pengembalian dari investasi perusahaan atas saham biasa.

Ukuran Perusahaan. Ukuran perusahaan berkaitan erat dengan teori agensi. Menurut Horne dan Wachowicz (2013:5), teori agensi adalah sebuah cabang dari ekonomi yang 
berhubungan dengan perilaku dari pemilik dan agen. Biaya agensi muncul ketika timbul biaya akibat menyelesaikan konflik kepentingan antara manajer dengan pemegang saham. Biaya agensi ini terdiri dari biaya pengawasan dan biaya untuk melakukan sistem pengendalian.

Pengukuran ukuran perusahaan menurut Pratt (2008:194), adalah dengan cara: (1) nilai pasar dari modal yang diinvestasikan, (2) total aset (yang dilaporkan dalam neraca), (3) rata-rata Earning Before Interest Tax Depreciation and Amortization (EBITDA) selama 5 tahun, (4) penjualan neto, (5) jumlah pekerja.

Ukuran Dewan Komisaris. Definisi dewan komisaris menurut Undang - Undang Perseroan Terbatas Nomor 40 Tahun 2007 Pasal 1 Ayat 6 adalah:

"Dewan Komisaris adalah Organ Perseroan yang bertugas melakukan pengawasan secara umum dan/atau khusus sesuai dengan anggaran dasar serta memberi nasehat kepada Direksi."

Wewenang, tugas dan tanggung jawab dewan komisaris secara lebih spesifik adalah: (1) Melakukan tugas dan tanggung jawab pengawasan atas kebijakan, pengurusan, jalannya pengurusan pada umumnya, dan memberikan nasehat kepada Direksi (Pasal 108 dan Pasal 114), (2) Bertanggung jawab renteng secara pribadi atas kerugian perseroan bila yang bersangkutan bersalah atau lalai dalam menjalankan tugasnya (Pasal 114 ayat 3 dan 4), (3) Bertanggung jawab renteng secara pribadi atas kepailitan perseroan bila disebabkan oleh kesalahan dan kelalaian dalam menjalankan tugas pengawasan dan pemberian nasehat (Pasal 115), (4) Diberi wewenang untuk membentuk komite yang diperlukan untuk mendukung tugas Dewan Komisaris.

Pengukuran ukuran dewan komisaris adalah jumlah dewan komisaris perusahaan (Crowther dan David ,2008: 142). Menurut Undang - Undang Perseroan Terbatas Nomor 40 Tahun 2007, jumlah dewan komisaris dalam perusahaan minimal 2 orang terdiri dari komisaris utama dan komisaris independen.

Hubungan Profitabilitas, Ukuran Perusahaan dan Ukuran Dewan Komisaris dengan Tanggung Jawab Sosial Perusahaan secara parsial dan simultan. Penelitian terdahulu atas pengaruh kinerja keuangan, ukuran perusahaan dan ukuran dewan komisaris terhadap pengungkapan tanggung jawab sosial perusahaan telah banyak dilakukan. Eddy Rismanda Sembiring (2005) meneliti Karakteristik Perusahaan dan Pengungkapan Tanggung Jawab Sosial: Studi Empiris pada Perusahaan yang Tercatat di Bursa Efek Jakarta. Penelitian ini menggunakan semua perusahaan yang tercatat di Bursa Efek Jakarta (BEJ) seperti yang tercantum dalam Indonesian Capital Market Directory 2002. Sampel penelitian yang diambil adalah 78 perusahaan. Hasil penelitian tersebut menemukan bahwa ukuran perusahaan dan ukuran dewan komisaris berpengaruh positif terhadap pengungkapan tanggung jawab sosial perusahaan.

Rita Yuliana, Bambang Purnomosidhi, dan Eko Ganis Sukoharsono (2008) meneliti Pengaruh Karakteristik Perusahaan Terhadap Pengungkapan Corporate Social Responsibility dan Dampaknya Terhadap Reaksi Investor. Sampel yang digunakan adalah 116 perusahaan. Metode pengambilan sampel yang digunakan dalam penelitian tersebut adalah sampel bertujuan (purposive sampling). Hasil penelitian tersebut menemukan bahwa ukuran, kinerja keuangan ( $R O A$ dan $R O E$ ) perusahaan tidak berpengaruh terhadap tingkat keluasan pengungkapan tanggung jawab sosial perusahaan. 
R.M. Haniffa dan T.E. Cooke (2005) meneliti The Impact of Culture and Governance on Corporate Social Reporting. Sampel yang digunakan adalah 139 perusahaan di Malaysia. Metode pengambilan sampel yang digunakan adalah metode acak. Hasil penelitian tersebut menemukan bahwa ukuran perusahaan dan $R O E$ berpengaruh signifikan terhadap luas pengungkapan tanggung jawab sosial perusahaan lebih besar.

Hazan Fauzi, Lois S. Mahoney, dan Azhar Abdul Rahman (2007) meneliti The Link between Corporate Social Performance and Financial Performance: Evidence from Indonesian Companies. Sampel yang digunakan berjumlah 383 perusahaan. Hasil penelitian tersebut menemukan bahwa hubungan antara kinerja sosial perusahaan dengan $R O A$ dan $R O E$ di Indonesia adalah negatif.

Anggraini (2006) meneliti Pengungkapan Informasi Sosial dan Faktor-Faktor yang Mempengaruhi Pengungkapan Informasi Sosial dalam Laporan Keuangan Tahunan: Studi Empiris pada Perusahaan-Perusahaan yang terdaftar Bursa Efek Jakarta. Sampel yang digunakan adalah 1188 perusahaan. Metode pengambilan sampel yang digunakan adalah purposive sampling. Hasil penelitian tersebut menemukan bahwa ukuran perusahaan tidak berpengaruh terhadap tingkat keluasan pengungkapan tanggung jawab sosial perusahaan.

Sandra A. Waddock dan Samuel B. Graves (1997) meneliti The Corporate Social Performance-Financial Performance Link. Sampel yang digunakan adalah 469 perusahaan. Metode pengambilan sampel yang digunakan adalah purposive sampling. Hasil penelitian tersebut menemukan bahwa ROA dan ROE yang lebih baik meningkatkan tingkat kinerja sosial perusahaan. Selain itu, kinerja sosial perusahaan yang baik meningkatkan $R O A$ dan $R O E$.

Aditya Dharmawan Krisna dan Novrys Suhardianto (2016) meneliti Faktor-Faktor yang Mempengaruhi Pengungkapan Tanggung Jawab Sosial. Sampel yang digunakan adalah 76 perusahaan. Metode pengambilan sampel yang digunakan adalah purposive sampling. Hasil penelitian tersebut menemukan bahwa profitabilitas, leverage, kepemilikan institusional, ukuran dewan komisaris, dan ukuran dewan direksi tidak berpengaruh terhadap luas pengungkapan tanggung jawab sosial perusahaan.

Berdasarkan uraian diatas, maka dapat dirumuskan hipotesis sebagai berikut ini:

$\mathrm{Ha}_{1}$ : ROA berpengaruh signifikan terhadap pengungkapan tanggung jawab sosial perusahaan pada perusahaan manufaktur terdaftar di BEI.

$\mathrm{Ha}_{2}$ : $R O E$ berpengaruh signifikan terhadap pengungkapan tanggung jawab sosial perusahaan pada perusahaan manufaktur terdaftar di BEI.

Ha3: Ukuran perusahaan berpengaruh signifikan terhadap pengungkapan tanggung jawab sosial perusahaan pada perusahaan manufaktur terdaftar di BEI.

Ha4: Ukuran dewan komisaris berpengaruh signifikan terhadap pengungkapan tanggung jawab sosial perusahaan pada perusahaan manufaktur terdaftar di BEI.

Ha5: $R O A, R O E$, ukuran perusahaan dan ukuran dewan komisaris secara bersama-sama berpengaruh signifikan terhadap pengungkapan tanggung jawab sosial perusahaan pada perusahaan manufaktur yangterdaftar di BEI.

\section{METODE}

Populasi dan Sampel Penelitian. Populasi dalam penelitian ini adalah semua perusahaan manufaktur yang terdaftar di BEI. Metode pemilihan sampel yang digunakan dalam 
penelitian ini adalah metode tidak acak (non-random sampling). Teknik pemilihan sampel yang digunakan adalah teknik pemilihan sampel tak acak bertujuan (purposive sampling) agar mendapatkan sampel yang sesuai dengan kriteria yang telah ditentukan. Kriteria yang ditentukan untuk menjadi sampel didasarkan pada tujuan penelitian (Aritonang R.,2007:103). Tujuan penelitian ini adalah meneliti pengaruh profitabilitas, ukuran perusahaan dan ukuran dewan komisaris terhadap pengungkapan tanggung jawab sosial perusahaan. Berdasarkan tujuan penelitian ini, kriteria pengambilan sampel adalah sebagai berikut: (1) Perusahaan manufaktur yang terdaftar di BEI pada periode 2014-2016, (2) mempublikasikan laporan tahunan pada periode 2014-2016, (3) mengungkapkan tanggung jawab sosial perusahaan dalam laporan tahunan tahun 2014-2016, (4) melaporkan laporan keuangan dalam Rupiah.

Operasionalisasi dan Pengukuran Variabel. Variabel Independen. Variabel independen dalam penelitian ini adalah profitabilitas (ROA dan ROE), ukuran perusahaan dan ukuran dewan komisaris. ROA diperoleh dari perbandingan antara net income dengan average total assets; dan $R O E$ diperoleh dari perbandingan antara net income dengan average total equities. Ukuran perusahaan diukur dengan menghitung jumlah aset (log total assets) yang dimiliki oleh perusahaan yang diperoleh dari neraca perusahaan. Ukuran dewan komisaris adalah jumlah dewan komisaris pada perusahaan manufaktur.

Variabel Dependen. Variabel Dependen dalam penelitian ini adalah pengungkapan tanggung jawab sosial perusahaan. Pengukuran indeks pengungkapan tanggung jawab sosial perusahaan yang digunakan dalam penelitian ini mengacu pada indikator pengungkapan tanggung jawab sosial perusahaan menurut Global Reporting Initiative $(G R I)$. Rumus untuk perhitungan indeks pengungkapan tanggung jawab sosial adalah:

Keterangan:

$$
\operatorname{CSR}_{j}=\frac{\sum X_{i j}}{n_{j}}
$$

CSRIj : Indeks pengungkapan tanggung jawab sosial perusahaan $\mathrm{j}$

$\mathrm{n}_{\mathrm{j}} \quad$ : Jumlah butir pengungkapan untuk perusahaan $\mathrm{j}, \mathrm{n}_{\mathrm{j}} \leq 91$

$\mathrm{X}_{\mathrm{ij}} \quad$ : dummy variable: jika butir pengungkapan diungkapkan= 1; jika butir pengungkapan tidak diungkapkan $=0$

Dengan demikian, $0 \leq C S R I_{\mathrm{j}} \leq 1$

Teknik Pengolahan Data. Penelitian ini menggunakan teknik analisis statistik yaitu analisis regresi berganda untuk uji empirisnya dengan SPSS (Statistical Product and Services) versi 23.0. Analisis regresi linier berganda digunakan untuk menganalisis hubungan linear antara dua variabel independen atau lebih dengan satu variabel dependen. Model regresi linear berganda dipergunakan untuk mengetahui apakah terdapat pengaruh variabel independen terhadap variabel dependen dan untuk mengetahui besar pengaruh masing-masing variabel independen terhadap variabel dependen.

Persamaan regresi berganda yang digunakan untuk tujuan penelitian ini, dikaitkan dengan hipotesis penelitian adalah sebagai berikut (Aritonang $\mathrm{R}, 2007: 75$ ):

Dimana:

$$
\mathrm{Y}=\mathrm{a}+\mathrm{b}_{1} \mathrm{X}_{1}+\mathrm{b}_{2} \mathrm{X}_{2}+\mathrm{b}_{3} \mathrm{X}_{3}+\mathrm{b}_{4} \mathrm{X}_{4}+\varepsilon
$$

$\mathrm{Y}=$ Nilai variabel dependen yang diprediksi, dalam penelitian ini, indeks pengungkapan tanggung jawab sosial perusahaan 
$\mathrm{a}=$ Koefisien konstanta, yaitu yaitu nilai variabel dependen yang diprediksi jika nilai tiap prediktornya sama dengan nol

$b_{1}, b_{2}, b_{3}, b_{4}=$ Koefisien regresi parsial, yaitu besarnya perubahan nilai variabel dependen yang diprediksi jika prediktor lainnya bernilai tetap

$\mathrm{X}_{1}=$ Nilai variabel independen Return on Asset (ROA)

$\mathrm{X}_{2}=$ Nilai variabel independen Return on Equity $(R O E)$

$\mathrm{X}_{3}=$ Nilai variabel independen ukuran perusahaan

$\mathrm{X}_{4}=$ Nilai variabel independen ukuran dewan komisaris

$\varepsilon=$ Error

Persamaan yang diperoleh dari proses regresi harus diuji secara statistik koefisien regresinya dengan SPSS. Apabila semua koefisien regresi signifikan, maka persamaan regresi yang diperoleh dapat digunakan untuk memprediksi nilai variabel terikat jika nilai variabel-variabel bebas ditentukan. Sebelum dilakukan pengujian terhadap model regresi, maka dilakukan uji asumsi klasik terlebih dahulu. Uji asumsi klasik yang dilakukan dalam penelitian ini terdiri dari uji normalitas, uji multikolinearitas, dan uji heteroskedastisitas.

Uji normalitas data dilakukan untuk mengetahui apakah data yang diambil telah mengikuti sebaran distribusi normal. Pengujian normalitas dalam penelitian ini menggunakan uji Kolmogorov-Smirnov. Jika probabilitas value atau Asymp. sig. 2-tailed lebih besar dari tingkat $\alpha$ yang ditetapkan yaitu 5\% maka data telah normal atau memenuhi persyaratan normalitas.

Uji multikolinearitas dilakukan untuk mengetahui apakah tiap-tiap variabel independen yang terdapat dalam model regresi memiliki hubungan linear yang sempurna atau mendekati sempurna. Model regresi yang baik seharusnya tidak terjadi korelasi sempurna atau mendekati sempurna di antara variabel besanya. Uji multikolinearitas dalam penelitian ini dilakukan dengan melihat nilai tolerance dan inflation factor (VIF) pada model regresi. Jika nilai VIF $<10$ dan angka tolerance lebih dari 0,1 maka variabel tersebut bebas dari multikolinearitas.

Uji heteroskedastisitas bertujuan untuk menguji apakah dalam suatu model regresi terjadi ketidaksamaan varian dari residual satu pengamatan ke pengamatan yang lain. Jika varian dari residual satu pengamatan ke pengamatan lain tetap, maka disebut homoskedastisitas, jika varian berbeda maka dinamakan heteroskedastisitas. Suatu model regresi yang baik adalah regresi yang tidak terjadi heteroskedastisitas. Penelitian ini menggunakan model uji Glesjer untuk menguji heteroskedastisitas. Jika probabilitas value atau Asymp. sig. 2-tailed lebih besar dari tingkat $\alpha$ yang ditetapkan yaitu 5\% maka tidak terjadi heteroskedastisitas.

\section{HASIL DAN PEMBAHASAN}

Uji Signifikansi Parameter Individual (Uji Statistik t). Pengujian di dalam koefisien regresi terdiri dari uji parsial (uji-t) dan uji simultan (uji-F). Uji parsial pada dasarnya menunjukkan seberapa besar pengaruh variabel independen secara individual dalam menerangkan variabel dependen.

Tabel 1. Uji t tahun 2014

Coefficients $^{\mathrm{a}}$ 


\begin{tabular}{|c|c|c|c|c|c|c|}
\hline \multirow{2}{*}{\multicolumn{2}{|c|}{ Model }} & \multicolumn{2}{|c|}{$\begin{array}{c}\text { Unstandardized } \\
\text { Coefficients }\end{array}$} & \multirow{2}{*}{$\begin{array}{c}\text { Standardized } \\
\text { Coefficients }\end{array}$} & \multirow[b]{2}{*}{$\mathrm{t}$} & \multirow[b]{2}{*}{ Sig. } \\
\hline & & $\mathrm{B}$ & Std. Error & & & \\
\hline \multirow[t]{5}{*}{1} & (Constant) & -.214 & .238 & & -.900 & .373 \\
\hline & ROA & .007 & .003 & .529 & 2.152 & .037 \\
\hline & ROE & -.001 & .002 & -.143 & -.595 & .555 \\
\hline & $\begin{array}{l}\text { UKURAN } \\
\text { PERUSAHAAN }\end{array}$ & .019 & .022 & .137 & .868 & .391 \\
\hline & UKURAN DK & .024 & .009 & .421 & 2.516 & .016 \\
\hline
\end{tabular}

a. Dependent Variable: CSRI

Pada Tabel 1 dapat dilihat bahwa pada tahun 2014 variabel $R O A$, ukuran perusahaan dan ukuran dewan komisaris memiliki pengaruh yang signifikan terhadap pengungkapan tanggung jawab sosial perusahaan pada perusahaan manufaktur di BEI. Sedangkan variabel $R O E$ tidak memiliki pengaruh signifikan terhadap pengungkapan tanggung jawab sosial perusahaan.

Tabel 2. Uji t tahun 2015

Coefficients $^{\mathrm{a}}$

\begin{tabular}{|c|c|c|c|c|c|c|}
\hline \multirow[b]{2}{*}{ Mod } & & \multicolumn{2}{|c|}{$\begin{array}{l}\text { Unstandardized } \\
\text { Coefficients }\end{array}$} & \multirow{2}{*}{$\begin{array}{c}\begin{array}{c}\text { Standardized } \\
\text { Coefficients }\end{array} \\
\text { Beta }\end{array}$} & \multirow[b]{2}{*}{$\mathrm{t}$} & \multirow[b]{2}{*}{ Sig. } \\
\hline & & B & Std. Error & & & \\
\hline \multirow[t]{6}{*}{1} & (Constant) & -.298 & .221 & & -1.351 & .184 \\
\hline & ROA & .004 & .002 & .525 & 2.906 & .006 \\
\hline & ROE & -.001 & .001 & -.152 & -.917 & .365 \\
\hline & UKURAN & .028 & .020 & .214 & 1.389 & .172 \\
\hline & PERUSAHAAN & & & & & \\
\hline & UKURAN DK & .019 & .009 & .346 & 2.060 & .046 \\
\hline
\end{tabular}

a. Dependent Variable: CSRI

Berdasarkan tampilan output Tabel 2 dapat dilihat bahwa pada tahun 2015 diperoleh hasil uji-t yaitu variabel $R O A$ dan ukuran dewan komisaris memiliki pengaruh yang signifikan terhadap pengungkapan tanggung jawab sosial perusahaan pada perusahaan manufaktur di BEI. Sedangkan variabel $R O E$ dan ukuran perusahaan tidak memiliki pengaruh signifikan terhadap pengungkapan tanggung jawab sosial perusahaan.

Berdasarkan Tabel 3 uji-t pada tahun 2016 menunjukkan bahwa variabel ROA dan ukuran dewan komisaris memiliki pengaruh yang signifikan terhadap pengungkapan tanggung jawab sosial perusahaan di tahun 2016 pada perusahaan manufaktur di BEI. Sedangkan variabel $R O E$ dan ukuran perusahaan tidak memiliki pengaruh signifikan terhadap pengungkapan tanggung jawab sosial perusahaan.

Tabel 3. Uji t tahun 2016 


\begin{tabular}{|c|c|c|c|c|c|c|}
\hline \multicolumn{7}{|c|}{ Coefficients $^{a}$} \\
\hline & \multirow[b]{2}{*}{ Model } & \multicolumn{2}{|c|}{$\begin{array}{c}\text { Unstandardized } \\
\text { Coefficients }\end{array}$} & \multirow{2}{*}{$\begin{array}{c}\text { Standardized } \\
\text { Coefficients }\end{array}$} & \multirow[b]{2}{*}{$\mathrm{t}$} & \multirow[b]{2}{*}{ Sig. } \\
\hline & & $\mathrm{B}$ & Std. Error & & & \\
\hline 1 & (Constant) & -.008 & .148 & & -.052 & .959 \\
\hline & $\mathrm{ROA}$ & .006 & .002 & .613 & 2.271 & .028 \\
\hline & ROE & .000 & .001 & -.068 & -.266 & .792 \\
\hline & $\begin{array}{l}\text { UKURAN } \\
\text { PERUSAHAAN }\end{array}$ & .003 & .013 & .025 & .219 & .827 \\
\hline & UKURAN DK & .021 & .007 & .360 & 2.752 & .009 \\
\hline
\end{tabular}

a. Dependent Variable: CSRI

Uji -F (ANOVA). Pengujian hipotesis berikut adalah uji secara simultan dengan menggunakan uji-F (ANOVA). Uji-F didasarkan pada nilai $F$ hitung dan tingkat signifikansi.

Tabel 4. Uji-F (ANOVA) tahun 2014

\begin{tabular}{llrrrrr}
\multicolumn{7}{c}{ ANOVA $^{\mathbf{b}}$} \\
\hline Model & Sum of Squares & df & Mean Square & F & Sig. \\
\hline 1 & Regression & .236 & 4 & .059 & 13.495 & $.000^{\mathrm{a}}$ \\
& Residual & .179 & 41 & .004 & & \\
\multicolumn{2}{l}{ Total } & .416 & 45 & & & \\
\multicolumn{2}{l}{ a. Predictors: (Constant), UKURAN DK, ROA, UKURAN PERUSAHAAN, ROE } \\
b. Dependent Variable: CSRI
\end{tabular}

Berdasarkan Tabel 4 uji-F tahun 2014 dapat dilihat tingkat signifikansi sebesar 0,000 dan nilai $\mathrm{F}$ hitung sebesar 13,945 dimana tingkat signifikansi tersebut lebih kecil dari 0,05 yang berarti Ha5 diterima sehingga dapat disimpulkan bahwa secara bersama - sama variabel independen ( $R O A, R O E$, ukuran perusahaan, dan ukuran dewan komisaris) mempunyai pengaruh yang signifikan terhadap pengungkapan tanggung jawab sosial perusahaan pada perusahaan manufaktur di BEI dengan tingkat keyakinan $95 \%$.

Tabel 5. Uji-F (ANOVA) tahun 2015

\begin{tabular}{llrrrrr}
\multicolumn{7}{c}{ ANOVA $^{\mathbf{b}}$} \\
\hline Model & & Sum of Squares & Df & Mean Square & F & Sig. \\
\hline 1 & Regression & .240 & 4 & .060 & 13.907 & $.000^{\mathrm{a}}$ \\
& Residual & .177 & 41 & .004 & & \\
& Total & .416 & 45 & & & \\
\hline
\end{tabular}

a. Predictors: (Constant), UKURAN DK, ROE, UKURAN PERUSAHAAN, ROA

b. Dependent Variable: CSRI

Berdasarkan tabel 5 uji-F tahun 2015 diperoleh tingkat signifikansi sebesar 0,000 dan nilai $\mathrm{F}$ hitung sebesar 13,907. Tingkat signifikansi tersebut lebih kecil dari 0,05 yang berarti Ha5 diterima sehingga dapat disimpulkan bahwa secara bersama - sama variabel 
independen ( $R O A$, $R O E$, ukuran perusahaan, dan ukuran dewan komisaris) mempunyai pengaruh yang signifikan terhadap pengungkapan tanggung jawab sosial perusahaan pada perusahaan manufaktur di BEI dengan tingkat keyakinan $95 \%$.

Tabel 6. Uji-F (ANOVA) tahun 2016

\begin{tabular}{llrrrrr}
\multicolumn{7}{c}{ ANOVA $^{\mathbf{b}}$} \\
\hline Model & & Sum of Squares & Df & Mean Square & F & Sig. \\
\hline 1 & Regression & .280 & 4 & .070 & 18.612 & $.000^{\mathrm{a}}$ \\
& Residual & .154 & 41 & .004 & & \\
& Total & .434 & 45 & & &
\end{tabular}

a. Predictors: (Constant), UKURAN DK, ROE, UKURAN PERUSAHAAN, ROA

b. Dependent Variable: CSRI

Dari Tabel 6 mengenai hasil uji-F tahun 2016 diperoleh tingkat signifikansi sebesar 0,000 dan nilai $\mathrm{F}$ hitung sebesar 18,612. Hal ini menunjukkan bahwa tingkat signifikansi lebih kecil dari 0,05 yang berarti Ha5 diterima sehingga bisa disimpulkan bahwa secara bersama - sama variabel independen (ROA, ROE, ukuran perusahaan dan ukuran dewan komisaris) mempunyai pengaruh yang signifikan terhadap variabel dependen pengungkapan tanggung jawab sosial perusahaan pada perusahaan manufaktur di BEI dengan tingkat keyakinan $95 \%$.

Tabel 7. Uji Multiple Determination tahun 2014

\begin{tabular}{llrrr}
\multicolumn{4}{c}{ Model Summary $^{\mathbf{b}}$} \\
\hline Model & $\mathrm{R}$ & R Square & $\begin{array}{c}\text { Adjusted R } \\
\text { Square }\end{array}$ & $\begin{array}{c}\text { Std. Error of the } \\
\text { Estimate }\end{array}$ \\
\hline 1 & $.754^{\mathrm{a}}$ & .568 & .526 & .066161874951 \\
\hline a. Predictors: (Constant), UKURAN DK, ROA, UKURAN PERUSAHAAN, ROE \\
b. Dependent Variable: CSRI
\end{tabular}

Tabel 7 Uji Multiple Determination tahun 2014 menunjukkan nilai R sebesar 0,754 yang berarti bahwa terdapat hubungan yang positif dan kuat. Kemudian nilai $\mathrm{R}$ square yang dihasilkan sebesar 0,568 atau $56,8 \%$ sehingga dapat disimpulkan bahwa sebesar $56,8 \%$ pengungkapan tanggung jawab sosial perusahaan dipengaruhi oleh variabel $R O A$, $R O E$, ukuran perusahaan dan ukuran dewan komisaris. Sementara sisanya 43,2\% dipengaruhi oleh faktor lain di luar model penelitian.

Tabel 8. Uji Multiple Determination tahun 2015

\begin{tabular}{lrrrr}
\multicolumn{4}{c}{ Model Summary $^{\mathbf{b}}$} \\
\hline Model & R & R Square & Adjusted R Square & Std. Error of the Estimate \\
\hline 1 & $.759^{\text {a }}$ & .576 & .534 & .065651836248 \\
\hline a. Predictors: (Constant), UKURAN DK, ROE, UKURAN PERUSAHAAN, ROA \\
b. Dependent Variable: CSRI
\end{tabular}


Berdasarkan Tabel 8 diketahui hasil uji multiple determination pada tahun 2015 adalah nilai $\mathrm{R}$ sebesar 0,759 dan nilai $\mathrm{R}$ square sebesar 0,576 atau sebesar $57,6 \%$. Hasil tersebut menunjukkan bahwa nilai $\mathrm{R}$ sebesar 0,759 memiliki arti adanya hubungan yang positif dan kuat, sedangkan nilai $\mathrm{R}$ square sebesar 0,576 berarti sebesar $57,6 \%$ pengungkapan tanggung jawab sosial perusahaan dipengaruhi oleh variabel $R O A, R O E$, ukuran perusahaan, dan ukuran dewan komisaris. Sementara sisanya yakni 42,4\% dipengaruhi oleh aktor lain di luar model penelitian.

Tabel 9. Uji Multiple Determination tahun 2016

\begin{tabular}{|c|c|c|c|c|}
\hline \multicolumn{5}{|c|}{ Model Summary $^{\mathbf{b}}$} \\
\hline Model & $\mathrm{R}$ & R Square & Adjusted R Square & Std. Error of the Estimate \\
\hline 1 & $.803^{\mathrm{a}}$ & .645 & .610 & .061311157596 \\
\hline
\end{tabular}

Dari Tabel 9 mengenai uji koefisien determinasi tahun 2016 diperoleh nilai $\mathrm{R}$ sebesar 0,803 yang berarti terdapat hubungan yang kuat dan positif serta nilai R Square sebesar 0,645 atau $64,5 \%$ yang menunjukkan bahwa sebesar $64,5 \%$ pengungkapan tanggung jawab sosial perusahaan dipengaruhi oleh variabel $R O A, R O E$, ukuran perusahaan dan ukuran dewan komisaris. Sementara sisanya sebesar 35,5\% dipengaruhi oleh faktor lain di luar model penelitian.

Keterbatasan Penelitian. Penelitian tersebut masih memiliki beberapa keterbatasan, yakni: (1) Jumlah variabel independen yang diteliti hanya variabel $R O A, R O E$, ukuran perusahaan dan ukuran dewan komisaris, padahal tanggung jawab sosial perusahaan diduga dapat dipengaruhi oleh faktor - faktor lainnya seperti peraturan pemerintah, tekanan dari masyarakat, leverage, profil perusahaan, ukuran kantor akuntan publik dan kualitas komite audit. (2) Periode pengamatan hanya tiga tahun dimulai dari tahun 2014, 2015 dan 2016.

\section{PENUTUP}

Simpulan. Berdasarkan uji-t pada tahun 2014, 2015 dan 2016 secara parsial $R O E$ dan ukuran perusahaan tidak berpengaruh signifikan terhadap pengungkapan tanggung jawab sosial perusahaan dengan tingkat keyakinan 95\%. Hasil ini sejalan dengan penelitian Hazan Fauzi, Lois S. Mahoney, Azhar Abdul Rahman (2007) dan penelitian Anggraini (2006).

Berdasarkan uji-t pada tahun 2014, 2015 dan 2016, variabel ROA dan ukuran dewan komisaris berpengaruh positif signifikan terhadap pengungkapan tanggung jawab sosial perusahaan secara parsial. Hasil ini sejalan dengan penelitian Jean B. McGuire, Alison Sundgren, Thomas Schneeweis (1988) dan penelitian Eddy Rismanda Sembiring (2005).

Berdasarkan uji-F tahun 2014, 2015 dan 2016 diperoleh hasil bahwa variabel ROA, $R O E$, ukuran perusahaan dan ukuran dewan komisaris secara bersama - sama berpengaruh signifikan terhadap pengungkapan tanggung jawab sosial perusahaan dengan tingkat keyakinan $95 \%$. 
Berdasarkan uji koefisien determinasi di tahun 2014, variabel pengungkapan tanggung jawab sosial perusahaan dipengaruhi oleh variabel $R O A, R O E$, ukuran perusahaan dan ukuran dewan komisaris sebanyak 56,8\% sedangkan sisanya 43,2\% dipengaruhi oleh faktor - faktor lain di luar model pengamatan. Pada tahun 2015, variabel pengungkapan tanggung jawab sosial perusahaan dipengaruhi oleh variabel $R O A, R O E$, ukuran perusahaan dan ukuran dewan komisaris sebanyak 57,6\% sedangkan sisanya 42,4\% dipengaruhi oleh faktor - faktor di luar model pengamatan. Pada tahun 2016, variabel pengungkapan tanggung jawab sosial perusahaan dipengaruhi oleh variabel $R O A$, $R O E$, ukuran perusahaan dan ukuran dewan komisaris sebanyak $64,5 \%$ sedangkan sisanya $35,5 \%$ dipengaruhi oleh faktor - faktor lain di luar model pengamatan seperti peraturan pemerintah, tekanan dari masyarakat, leverage, profil perusahaan, ukuran kantor akuntan publik, dan kualitas komite audit.

Saran. Bagi penelitian selanjutnya sebaiknya menggunakan periode yang lebih panjang dan sampel yang lebih banyak agar didapatkan hasil yang lebih akurat. Penelitian ini juga hanya menggunakan variabel $R O A, R O E$, ukuran perusahaan dan ukuran dewan komisaris, sedangkan masih terdapat faktor - faktor lain yang mempengaruhi pengungkapan tanggung jawab sosial perusahaan namun diharapkan penelitian ini dapat memberikan wawasan penelitian yang lebih luas lagi sehingga untuk riset selanjutnya dapat digunakan variabel yang lebih banyak lagi seperti kualitas komite audit, peraturan pemerintah, tekanan dari masyarakat dalam meneliti pengaruhnya terhadap pengungkapan tanggung jawab sosial perusahaan.

\section{DAFTAR RUJUKAN}

Anggraini, Fr. R. R. (2006). Pengungkapan Informasi Sosial dan Faktor-faktor yang Mempengaruhi Pengungkapan Informasi Sosial dalam Laporan Keuangan Tahunan.

Simposium Nasional Akuntansi IX. Padang. 23-26 Agustus.

Aritonang, Lerbin R., (2007). Riset Pemasaran: Teori dan Praktik. Bogor: Ghalia Indonesia.

Brigham, E. dan J. Houston. (2001). Manajemen Keuangan. Erlangga. Jakarta.

Crowther David. (2008). Corporate Social Responsibility. Guler Aras \& Ventus Publishing ApS.

Fauzi, Hazan; Lois S. Mahoney, dan Azhar Abdul. (2007). The Link between Corporate Social Performance and Financial Performance: Evidence from Indonesian Companies. Social and Environmental Accounting vol. 1, June 2007

Global Reporting Initiative. (2013). G4 Sustaina-bility Reporting Guidelines: Reporting Principles and Standard Disclosures. Amsterdam: Global Reporting Initiative

Haniffa, R.M., dan Cooke, T.E. (2005). "The impact of culture and governance on corporate social reporting". Journal of Accounting and Public Policy.

Kotler, Philip dan Nancy Lee. (2005). Corporate Social Responsibility; Doing the Most Good you're your Company and Your Cause. New Jersey; JohnWiley \& Sons, Inc.

Krisna, Aditya Dharmawan, dan Novrys Suhardianto. (2016). "Faktor-Faktor yang Mempengaruhi Pengungkapan Tanggung Jawab Sosial Perusahaan". Jurnal Akuntansi dan Keuangan, 18 (2). 
Lawrence, Anne T dan Weber, James., (2011). Business and Society : Stakeholders, Ethics, Public Policy, Thirteenth Edition, McGraw Hill International Edition

McGuire, Jean B., Alison Sundgren; dan Thomas Schneeweis. (1988). Corporate Social Responsibility and Firm Financial Performance. The Academy of Management Journal, 31 (4).

Ross, Westerfield dan Jordan. (2009). Corporate Finance Fudamentals: Pengantar Keuangan Perusahaan. Terjemahan Ali Akbar Yulianto, Rafika Yuniasih dan Christine. Jakarta: Salemba empat

Sembiring, Eddy Rismanda. (2005). "Karakteristik Perusahaan dan Pengungkapan Tanggung Jawab Sosial: Studi Empiris pada Perusahaan yang tercatat di Bursa Efek Jakarta". Simposium Nasional Akuntansi 8. Solo. 15-16 September 2005.

Putri, Rani Widiyasari Eko; dan Zaki Baridwan. (2013). "Pengaruh Profitabilitas terhadap Corporate Social Responsibility Studi Empiris pada Perusahaan Tambang yang Terdaftar di Bursa Efek Indonesia”. Jurnal Ilmiah Universitas Brawijaya, 2 (2).

Weygandt, Jerry J., Paul D. Kimmel, dan Donal E. Kieso. (2016). Financial Accounting, 3ed. IFRS Edition. USA: John Wiley \& Sons, Inc.

Wibisono, Yusuf, (2007). Membedah Konsep \& Aplikasi Corporate Social Responsibility, Gresik: Fascho Publishing.

Waddock, S. A., \& Graves, S. B. (1997). "The Corporate Social Performance. Financial Performance Link", Strategic Management Journal, 18 (4), 303-319.

Yuliana, Rita, Bambang Purnomosidhi, dan Eko Ganis Sukoharsono. (2008). "Pengaruh Karakteristik Perusahaan terhadap Pengungkapan Corporate Social Responsibility (CSR) dan Dampaknya terhadap Reaksi Investor". Jurnal Akuntansi dan Keuangan Indonesia, 5 (2). 